\title{
Pseudomonas aeruginosa in cystic fibrosis: role of mucC in the regulation of alginate production and stress sensitivity
}

\author{
J. C. Boucher, M. J. Schurr, H. Yu, D. W. Rowen and V. Deretic \\ Author for correspondence: V. Deretic. Tel: +1 313763 1580. Fax: +1 3136476243. \\ e-mail: deretic@umich.edu
}

Department of Microbiology and Immunology, University of Michigan, Medical School, Ann Arbor, Ml 48109-0620, USA

\begin{abstract}
Alginate production in Pseudomonas aeruginosa and the associated mucoid phenotype of isolates from cystic fibrosis patients are under the control of the algU muCABCD cluster. This group of genes encodes AlgU, the $P$. aeruginosa equivalent of the extreme heat shock $\sigma$ factor $\sigma^{F}$ in Gram-negative bacteria, the AlgU-cognate anti- $\sigma$ factor MucA, the periplasmic protein MucB and a serine protease homologue, MucD. While mucA, muCB or mucD act as negative regulators of AlgU, the function of mucC is not known. In this study the role of mucC in $P$. aeruginosa physiology and alginate production has been addressed. Insertional inactivation of mucC in the wild-type $P$. aeruginosa strain PAO1 did not cause any overt effects on alginate synthesis. However, it affected growth of $P$. aeruginosa under conditions of combined elevated temperature and increased ionic strength or osmolarity. Inactivation of mucC in muCA or mucB mutant backgrounds resulted in a mucoid phenotype when the cells were grown under combined stress conditions of elevated temperature and osmolarity. Each of the stress factors tested separately did not cause comparable effects. The combined stress factors were not sufficient to cause phenotypically appreciable enhancement of alginate production in mucA or muCB mutants unless mucC was also inactivated. These findings support a negative regulatory role of mucC in alginate production by $P$. aeruginosa, indicate additive effects of muc genes in the regulation of mucoidy in this organism and suggest that multiple stress signals and recognition systems participate in the regulation of algU-dependent functions.
\end{abstract}

Keywords: sigma factors, anti-sigma, mucoidy

\section{INTRODUCTION}

Conversion of Pseudomonas aeruginosa into the mucoid, exopolysaccharide alginate-overproducing phenotype is usually associated with chronic colonization of the respiratory tract in cystic fibrosis (Govan \& Deretic, 1996). While mucoid $P$. aeruginosa can also be encountered in other chronic infections (Govan \& Deretic, 1996), mucoid colony morphology is rare among environmental isolates which can produce alginate but only at very low levels (Anastassiou et al., 1987; Pier $e t$ al., 1986). Recent analyses have shown that the conversion to mucoidy in cystic fibrosis isolates is frequently caused by mutations in the mucA gene (Boucher et al.,

Abbreviation: PIA, Pseudomonas isolation agar.
1996; Deretic et al., 1994, 1995; Martin et al., 1993c; Yu et al., 1996). This gene is located within the algU mucABCD cluster at 67.5 min (Boucher et al., 1996; Martin et al., 1993a, b). The genes within this cluster and their organization are highly conserved in Gramnegative bacteria (Fig. 1a). In P. aeruginosa this locus encodes the following elements. (i) The $\sigma$ factor AlgU [also known as AlgT (DeVries \& Ohman, 1994) or Pa $\sigma^{\mathrm{E}}$ (Deretic et al., 1994)] is a member of the AlgU-RpoE subfamily of alternative $\sigma$ factors (Deretic et al., 1995; Lonetto et al., 1994; Yu et al., 1996). P. aeruginosa AlgU and its equivalent in enteric bacteria, $\sigma^{\mathrm{E}}$, control extreme stress responses in these organisms (Erickson \& Gross, 1989; Martin et al., 1994; Raina et al., 1995; Rouviére et al., 1995; Yu et al., 1995). (ii) The anti- $\sigma$ factor MucA which associates with AlgU and inhibits its function (Schurr et al., 1996; Xie et al., 1996). (iii) The periplasmic 
Table 1. Bacterial strains and plasmids

\begin{tabular}{|c|c|c|}
\hline Bacterial strain or plasmid & Relevant genotype or properties* & Source or reference \\
\hline \multicolumn{3}{|l|}{ P. aeruginosa } \\
\hline PAO1 & Prototroph Alg ${ }^{-w t}$ & $\begin{array}{r}\text { B. Holloway (Monash } \\
\text { University, Australia) }\end{array}$ \\
\hline PAO568 & PAO381 $\mathrm{Alg}^{+\mathrm{m}} m u c A 2$ & Fyfe \& Govan (1980) \\
\hline PAO6857 & PAO1 $\mathrm{Alg}^{+\mathrm{m}} m u c B:: \mathrm{Tc}^{\mathrm{r}}$ & Schurr et al. (1996) \\
\hline PAO6875 & PAO1 $\mathrm{Alg}^{-\mathrm{wt}}$ mucC:: $\mathrm{Gm}^{\mathrm{r}}$ & This work \\
\hline PAO6876 & PAO568 $\mathrm{Alg}^{+\mathrm{NaCl}} m u c C:: \mathrm{Gm}^{\mathrm{r}}$ & This work \\
\hline PAO6877 & PAO6857 $\mathrm{Alg}^{+ \text {Suc }} m u c C:: \mathrm{Gm}^{\mathrm{r}}$ & This work \\
\hline PAO6858 & PAO568 $\mathrm{Alg}^{+c} m u c B:: \mathrm{Tc}^{\mathrm{r}}$ & This work \\
\hline \multicolumn{3}{|l|}{ Plasmids } \\
\hline pkI11G & pUC18 $\mathrm{Gm}^{\mathrm{r}}$ cassette & $\begin{array}{l}\text { S. Lory (University of } \\
\text { Washington, USA) }\end{array}$ \\
\hline pCMobA & $\mathrm{pHC} 79 m o b^{+}$ & Mohr \& Deretic $(1990)$ \\
\hline pBSC1 & pCRII $m o b^{+} m u c C:: \mathrm{Gm}^{\mathrm{r}}$ & This work \\
\hline $\mathrm{p} t a c-m u c d^{+}$ & IncQ/P4 tac-mucD ${ }^{+} l a c I^{\mathrm{q}} \mathrm{Cb}^{\mathrm{r}}$ & Boucher et al. (1996) \\
\hline
\end{tabular}

" $\mathrm{Alg}^{+\mathrm{c}}$, constitutive mucoid phenotype; $\mathrm{Alg}^{+\mathrm{m}}$, mucoid phenotype dependent on medium; $\mathrm{Alg}^{+\mathrm{NaCl}}$, enhanced mucoid phenotype when grown on LB supplemented with $90 \mathrm{mM} \mathrm{NaCl} ; \mathrm{Alg}^{+\mathrm{Suc}}$, enhanced mucoid phenotype when grown on LB supplemented with $30 \%$ sucrose; $\mathrm{Alg}^{-\mathrm{wt}}$, wild-type non-mucoid phenotype.

protein MucB (Martin et al., 1993b; Schurr et al., 1996), also known as AlgN (Goldberg et al., 1993), which displays negative effects on AlgU-dependent expression. (iv) MucC (Boucher et al., 1996), a protein of unknown function. (v) MucD (Boucher et al., 1996), a homologue of the periplasmic serine protease HtrA (DegP) (Lipinska et al., 1988; Strauch \& Beckwith, 1988), which has been proposed to remove signals (e.g. denatured or otherwise damaged proteins) or other factors activating $\mathrm{Alg} U$ (Boucher et al., 1996). The available genetic and biochemical evidence strongly supports the notion that MucA, MucB and MucD are negative regulators of AlgU activity.

$\mathrm{AlgU}\left(\mathrm{Pa} \sigma^{\mathrm{E}}\right)$ directs transcription of promoters characterized by the $\sigma^{\mathrm{E}}$ promoter consensus sequence -35 GAACTT $\left(\mathrm{N}_{16 / 17}\right)$ - 10 TCTgA (Deretic et al., 1994; Erickson \& Gross, 1989; Lam et al., 1980; Martin et al., 1993c; Schurr et al., 1995). In addition to the $P_{1}$ and $P_{3}$ promoters of AlgU (Schurr et al., 1995) at least two other genes critical for alginate production, $\operatorname{alg} D$ and algR, have $\sigma^{\mathrm{E}}$ promoters and depend on AlgU for transcription (Deretic et al., 1994; Martin et al., 1994; Wozniak \& Ohman, 1994). The algD gene encodes a key alginate biosynthetic enzyme, GDP-mannose dehydrogenase (May \& Chakrabarty, 1994), and is located at the beginning of the gene cluster at $34 \mathrm{~min}$ which also encodes additional alginate biosynthetic and modification enzymes with partial overlaps with LPS biogenesis (Coyne et al., 1994; May \& Chakrabarty, 1994). In other organisms, elements controlled by AlgU homologues have been implicated in the heat shock response (Erickson \& Gross, 1989), resistance to reactive oxygen intermediates (Johnson et al., 1991), virulence in mice (Elzer et al., 1996; Johnson et al., 1991) and survival under conditions of high pressure and extreme cold (Chi
$\&$ Bartlett, 1995). While the role of $m u c A, m u c B$ and $m u c D$ in the regulation of mucoidy in $P$. aeruginosa has been explored, very little is known about the function of $m u c C$. Here we present data indicating a negative regulatory role for $m u c C$. The effects of mucC are noticeable only in mucoid mutants and under conditions of environmental stress.

\section{METHODS}

Bacterial strains, plasmids and growth conditions. $P$. aeruginosa strains and plasmids used in this study are shown in Table 1. PAO6875, PAO6876 and PAO6877 were derivatives of PAO1, PAO568 (mucA2) and PAO6857 (mucB:: Tcr), respectively, with an inactivated $m u c C$ gene $\left(m u c C:: \mathrm{Gm}^{\mathrm{r}}\right)$. Strain PAO6858 is a $m u c B:: \mathrm{Tc}^{\mathrm{r}}$ derivative of PAO568. P. aeruginosa was grown on Pseudomonas isolation agar (PIA; Difco) or LB supplemented with $90 \mathrm{mM} \mathrm{NaCl}, 300 \mathrm{mM} \mathrm{NaCl}$, $30 \%(\mathrm{w} / \mathrm{v})$ sucrose, tetracycline $\left(300\right.$ or $50 \mu \mathrm{g} \mathrm{m}^{-1}$ for PIA or $\mathrm{LB}$, respectively) or gentamicin $\left(150\right.$ or $13 \mu \mathrm{g} \mathrm{ml}^{-1}$ for PIA or LB, respectively) when required. Escherichia coli was grown on LB supplemented with ampicillin $\left(100 \mu \mathrm{g} \mathrm{ml}^{-1}\right)$, kanamycin $\left(25 \mu \mathrm{g} \mathrm{ml} \mathrm{m}^{-1}\right)$ or gentamicin $\left(13 \mu \mathrm{g} \mathrm{ml} \mathrm{m}^{-1}\right)$ when required. Bacterial growth curves were determined as described previously (Boucher et al., 1996).

Genetic methods. Gene replacements and insertional inactivation of chromosomal genes were carried out as described previously (Martin et al., 1993b). The mucB and mucC genes were insertionally inactivated on the $P$. aeruginosa chromosome via homologous recombination using the non-replicative plasmids pDMB100 and pBSC1, respectively. For insertional inactivation of $m u c C$ on the chromosomes of PAO1, PAO568 and PAO6857, a $0.9 \mathrm{~kb}$ PCR product generated with the primers UL-9 $\left(5^{\prime}\right.$ TGAAGTCCGGCAGTT $\left.3^{\prime}\right)$ and UR-24 $\left(5^{\prime}\right.$ CGGCACCTGCCGAAGA $3^{\prime}$ ) was cloned into pCRII (Invitrogen). This construct was further modified by inserting the $X b a I$ linker $\mathrm{Gm}^{\mathrm{r}}$ cassette from $\mathrm{pKI} 11 \mathrm{G}$ into the AvrII site within $m u c C$, followed by cloning of $m o b$ from pCMobA into 
the HindIII site to generate pBSC1. Candidate strains with gene replacements via double cross-over events between plasmid and chromosome were isolated as $\mathrm{Gm}^{\mathrm{r}} \mathrm{Cb}^{\mathrm{s}}$ or $\mathrm{Tc}^{\mathrm{r}} \mathrm{Cb}^{\mathrm{s}}$ exconjugants selected by replica plating. All gene replacements were confirmed by Southern blot analysis.

Alginate assay. Production of alginate was determined by assaying uronic acids as described by Knutson \& Jeanes (1976).

\section{RESULTS}

\section{The mucC gene is required for growth under conditions of combined elevated temperature and high salt concentration}

The alg $U$ mucABCD cluster is conserved with minor variations in all Gram-negative bacteria investigated to date (Fig. 1a) (Schurr et al., 1996; Yu et al., 1996). The first four genes of the cluster, including $m u c C$, are present in the majority of the organisms in which the corresponding gene cluster has been analysed (Yu et al., 1996). To investigate the potential role of $m u c C$ in the regulation of $\mathrm{Alg} U$ and alginate production, we insertionally inactivated $m u c C$ in the standard genetic wild-type nonmucoid strain PAO1. Unlike inactivation of mucA, $m u c B$ or $m u c D$, which each individually cause conversion to mucoidy in PAO1 (Boucher et al., 1996; Martin et al., 1993b, c), disruption of the mucC gene on the chromosome did not result in visible morphological changes, i.e. the resulting strain, PAO6875 (mucC::Gm${ }^{r}$ ), remained non-mucoid (Table 2). These results suggest that the loss of $m u c C$ alone, in contrast to the other members of the mucABCD cluster (Boucher et al., 1996; Martin et al., 1993b, c), is not sufficient to alter the non-mucoid phenotype.

Since the MucC homologue from Photobacterium sp. strain SS9 (Chi \& Bartlett, 1995) appears to participate in the adaptation of this bacterium to adverse environmental conditions, we hypothesized that MucC may affect functions of AlgU other than alginate production, e.g. survival of $P$. aeruginosa at elevated temperatures and upon exposure to reactive oxygen intermediates (Martin et al., 1994; Yu et al., 1995). To test the possibility that mucC may affect $P$. aeruginosa viability, we compared growth characteristics of PAO6875 (mucC:: Gm ${ }^{\mathbf{r}}$ ) and its parent PAO1 $\left(m u c C^{+}\right)$ under conditions of environmental stress. No differences were observed in sensitivity to reactive oxygen intermediates (tested by exposure to paraquat or $\mathrm{H}_{2} \mathrm{O}_{2}$ ) or growth at $42{ }^{\circ} \mathrm{C}$, previously shown to adversely affect $P$. aeruginosa algU null strains (Martin et al., 1994). Since $\sigma^{\mathrm{E}}$ has been implicated in the response to osmolarity changes (Mecsas et al., 1993) and some mucoid $P$. aeruginosa strains have been observed to alter alginate production in the presence of osmolytes $(\mathrm{NaCl}$ or sucrose) (Deretic et al., 1990), we next tested whether mucC mutations can affect $P$. aeruginosa growth on high osmolarity media. No differences between PAO1 and PAO6875 (mucC::Gm ${ }^{\mathrm{r}}$ ) were observed on LB supplemented with $300 \mathrm{mM} \mathrm{NaCl}$ (data not shown). However, when a combination of factors was examined,
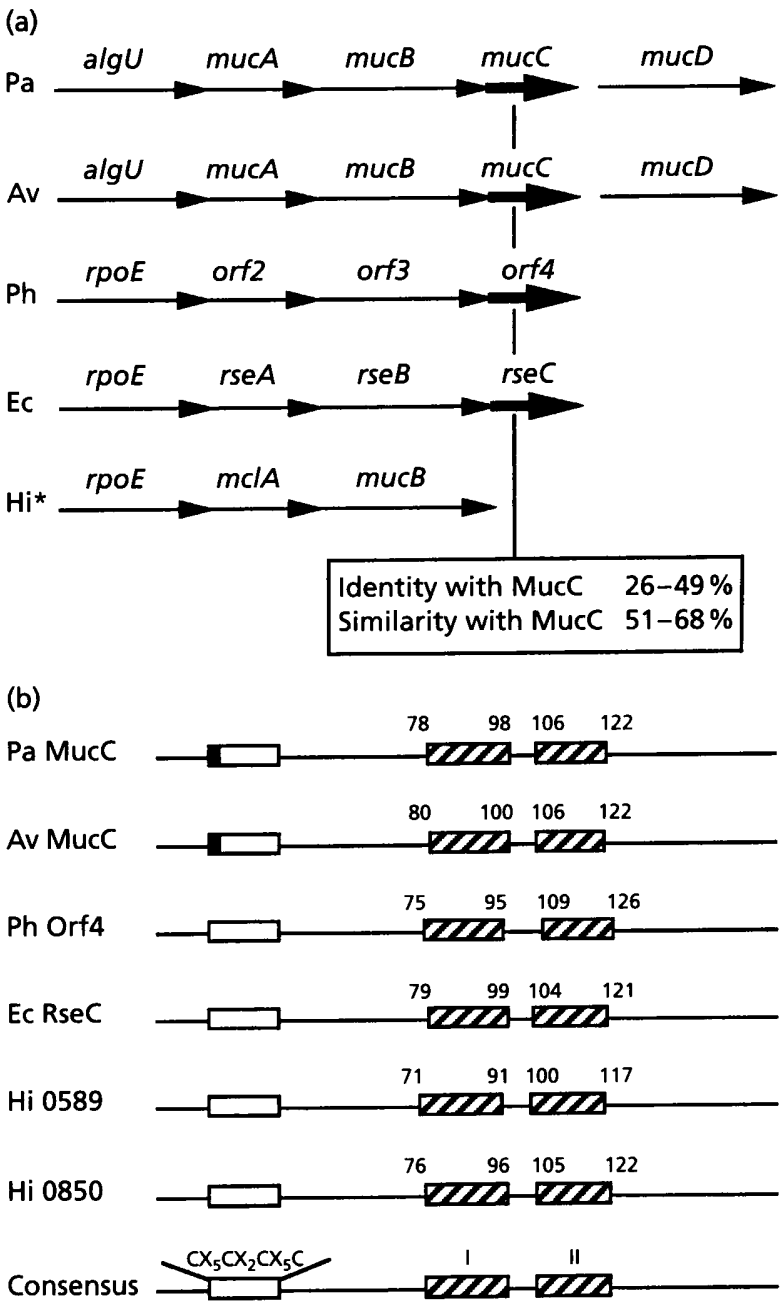

Fig. 1. Genetic organization of the alg $U$ muCABCD gene cluster which controls expression of mucoidy in $P$. aeruginosa, organization of its equivalents in other Gram-negative organisms and conservation of MucC homologues. (a) Genes and their functions. algU encodes the alternative $\sigma$ factor AlgU $\left(\mathrm{Pa} \sigma^{\mathrm{E}}\right.$ ) (Martin et al., 1993a; Yu et al., 1995). muCA is a common site of spontaneous mutations causing conversion to mucoidy in cystic fibrosis (Martin et al., 1993c); it encodes an anti- $\sigma$ factor which binds to AlgU and inhibits its activity (Schurr et al., 1996; Xie et al., 1996). mucB encodes a periplasmic protein which also acts as a negative regulator of mucoidy (Martin et al., 1993b; Schurr et al., 1996). mucC (Boucher et al., 1996) was shown in this study to play a negative regulatory role. mucD encodes a homologue of the serine protease HtrA (DegP) and has been proposed to remove denatured or damaged proteins, thus eliminating the signals activating the extreme stress $\sigma$ factor AlgU (Boucher et al., 1996). Pa, P. aeruginosa; Av, Azotobacter vinelandii; Ph, Photobacterium spp.; Ec, E. coli; $\mathrm{Hi}$, Haemophilus influenzae. The asterisk indicates that mucC homologues in Haemophilus influenzae are unlinked (see b). (b) Conservation of the putative transmembrane domains (I and II) and a motif present in MucC homologues resembling the sequence of the active centre of SoxR (Wu \& Weiss, 1991). Hatched boxes, predicted transmembrane domains; open boxes, the $\mathrm{CX}_{5} \mathrm{CX}_{2} \mathrm{CX}_{5} \mathrm{C}$ motif; filled portions of open boxes, $\mathrm{T}$ and $A$ instead of the first $C$ within the $\mathrm{Pa}$ and $\mathrm{Av}$ motifs, respectively. Numbers represent the position of charged amino acid residues demarcating each putative transmembrane domain. 
Table 2. Inactivation of mucC enhances alginate production in mucA and mucB mutants of $P$. aeruginosa

\begin{tabular}{|c|c|c|c|c|c|}
\hline \multirow[t]{3}{*}{ Strain $\nmid$} & \multirow[t]{3}{*}{ Genotype } & \multicolumn{4}{|c|}{$\begin{array}{l}\text { Phenotype: } \neq \\
\text { Alginate production }\left[\mu \mathrm{g}(\mathrm{mg} \text { wet wt of cells) })^{-1} \pm \mathrm{SE}\right] \mathbb{S}\end{array}$} \\
\hline & & \multirow[t]{2}{*}{ PIA } & \multicolumn{3}{|c|}{ LB } \\
\hline & & & $42^{\circ} \mathrm{C}$ & $\begin{array}{c}42{ }^{\circ} \mathrm{C} \\
90 \mathrm{nM} \mathrm{NaCl}\end{array}$ & $\begin{array}{l}42{ }^{\circ} \mathrm{C} \\
30 \% \text { sucrose }\end{array}$ \\
\hline PAO1 & $\operatorname{alg} U^{+} \operatorname{mucABCD^{+}}$ & NM $(1 \cdot 14 \pm 0 \cdot 05)$ & $\mathrm{NM}(1.93 \pm 0.14)$ & $N M(N D)$ & NM $(1.26 \pm 0.09)$ \\
\hline PAO6875 & mucC:: $\mathrm{Gm}^{\mathrm{r}}$ & NM $(2 \cdot 04 \pm 0.01)$ & $\mathrm{NM}(2.39 \pm 0.33)$ & NM (ND) & $\mathrm{NM}(1.20 \pm 0.08)$ \\
\hline PAO6857 & $m u c B:: \mathrm{Tc}^{\mathrm{r}}$ & $M(23.81 \pm 1.79)$ & $\mathrm{NM}(2.72 \pm 0.33)$ & NM (ND) & $\mathrm{NM}(1.47 \pm 0.16)$ \\
\hline PAO6877 & $\begin{array}{l}m u c B:: \mathrm{Tc}^{\mathrm{r}} \\
m u c C:: \mathrm{Gm}^{\mathrm{r}}\end{array}$ & $M(24.56 \pm 2 \cdot 25)$ & NM $(2 \cdot 82 \pm 0 \cdot 26)$ & $\mathrm{NM}(\mathrm{ND})$ & $M(7 \cdot 06 \pm 0 \cdot 11)$ \\
\hline PAO6877 & $\begin{array}{l}m u c B:: \mathrm{Tc}^{\mathrm{r}} \\
m u c C:: \mathrm{Gm}^{\mathrm{r}} \\
{\left[\mathrm{p} t a c-m u c D^{+}\right]}\end{array}$ & $M(\mathrm{ND})$ & $\mathrm{NM}(\mathrm{ND})$ & $\mathrm{NM}(\mathrm{ND})$ & $M(10 \cdot 82 \pm 0 \cdot 97)$ \\
\hline PAO568 & mucA2 & $M(86 \cdot 59 \pm 5 \cdot 35)$ & $\mathrm{NM}(1.64 \pm 0.08)$ & $M^{*}(4 \cdot 15 \pm 0 \cdot 32)$ & $M(\mathrm{ND})$ \\
\hline PAO6876 & $\begin{array}{l}\text { mucA2 } \\
m u c C:: \mathrm{Gm}^{\mathrm{r}}\end{array}$ & $M(84.37 \pm 9 \cdot 53)$ & NM $(2 \cdot 87 \pm 0 \cdot 08)$ & $M(14.19 \pm 1.77)$ & $M(N D)$ \\
\hline
\end{tabular}

† The strains PAO6875, PAO6857 and PAO6877 are derivatives of $P$. aeruginosa PAO1. Strain PAO6876 is a derivative of $P$. aeruginosa PAO568.

$\ddagger$ Phenotypes: NM, non-mucoid; $\mathrm{M}$, mucoid; $\mathrm{M}^{*}$, mucoid after $48 \mathrm{~h}$. Strains plated on PIA medium were grown at $37^{\circ} \mathrm{C}$. Strains plated on LB were grown at $42^{\circ} \mathrm{C}$ with indicated supplements.

$\$$ The $P$ values $\left(t\right.$ test) were $8.67 \times 10^{-6}$ for PAO6857 and PAO6877 grown at $42^{\circ} \mathrm{C}$ on LB in the presence of $30 \%$ sucrose and $5 \cdot 10 \times 10^{-3}$ for PAO568 and PAO6876 grown at $42^{\circ} \mathrm{C}$ on $\mathrm{LB}$ in the presence of $90 \mathrm{mM} \mathrm{NaCl}$.

i.e. growth at elevated temperature $\left(42^{\circ} \mathrm{C}\right)$ in the presence of $300 \mathrm{mM} \mathrm{NaCl}$, a dramatic effect of the mucC mutation on $P$. aeruginosa growth was observed (Fig. 2a). The mucC:: $\mathrm{Gm}^{\mathrm{r}}$ strain PAO6875 displayed severe inhibition of growth, similar to that seen in the algU mutant strain PAO6852 (Fig. 2a). The effect of $m u c C$ inactivation was not due to polar effects on $m u c D$, since the $m u c C$ mutant PAO6875 did not show increased sensitivity to $\mathrm{H}_{2} \mathrm{O}_{2}$ or retarded growth at $42{ }^{\circ} \mathrm{C}$ characteristic of $m u c D$ mutants. Furthermore, introduction of the plasmid ptac-mucD in PAO6875 did not complement the growth inhibition phenotype, although this plasmid complements the mucD mutation in strain PAO6860 (Boucher et al., 1996). However, several attempts to obtain a direct complementation of the chromosomal mucC mutation using the mucC gene cloned behind the tac promoter were inconclusive. The negative results of these complementation studies are complicated by the fact that mucC does not have a separate ribosome-binding site and is likely translationally coupled with $m u c B$, as reflected in the partial overlap of the last codon of mucB and the initiation codon of mucC in P. aeruginosa (Boucher et al., 1996). However, the specificity of effects of mucC inactivation is illustrated by the similar phenotypes of several independently obtained mucC mutants. In further support of the specificity of $m u c C$ inactivation, growth inhibition under the same conditions (Fig. 2b) was also observed in PAO6876, a
mucC strain made in a different genetic background. However, mucC inactivation did not significantly decelerate $P$. aeruginosa growth when sucrose was used as an osmolyte as exemplified in Fig. 2(c). These results suggest that mucC is required for uninhibited growth of $P$. aeruginosa under conditions of combined high salt concentration and elevated temperature.

\section{The mucC gene is a negative regulator of alginate production in mucoid mucA and mucB mutants}

Although inactivation of $m u c C$ in the non-mucoid wildtype strain PAO1 had an effect on its survival under conditions of combined elevated temperature and increased salt concentration in the medium, it did not affect the non-mucoid phenotype in the PAO1 background under such conditions (Table 2 ). In a converse set of experiments, we investigated whether the mucC gene may have an effect on alginate production in mucoid mutants. To test this, mucC was inactivated in $m u c A$ and $m u c B$ backgrounds and two double mutant strains, PAO6876 (mucA2 mucC:: $\mathrm{Gm}^{\mathrm{r}}$ ) and PAO6877 $\left(m u c B:: \mathrm{Tc}^{\mathrm{r}} m u c C:: \mathrm{Gm}^{\mathrm{r}}\right)$, were compared to their parental strains PAO568 (mucA2) and PAO6857 $\left(m u c B:: \mathrm{Tc}^{\mathrm{r}}\right)$, respectively. No effect on mucoidy (e.g. reduction or increase in alginate production) was seen in such strains grown on PIA, a medium that supports the mucoid phenotype in all $m u c$ mutants tested thus far (Table 2). Although mucA and $m u c B$ mutants of $P$. 

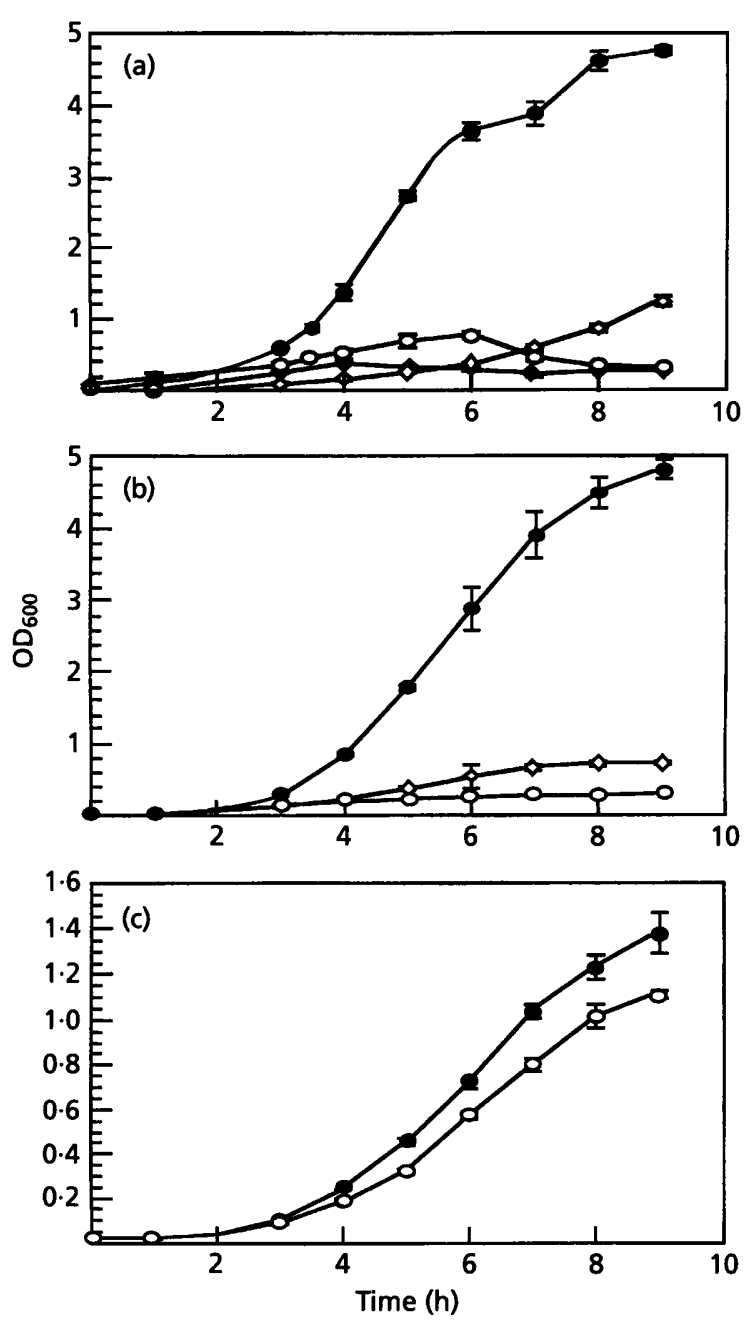

\begin{abstract}
Fig. 2. Effects of mucC inactivation on growth of $P$. aeruginosa under stress conditions. (a) Growth curves of PAO1 $\mathrm{algU}^{+}$ mucC $C^{+}(O)$, its mucC:: $\mathrm{Gm}^{\mathrm{r}}$ and algU:: $\mathrm{Tc}^{\mathrm{r}}$ isogenic derivatives, PAO6875 $(O)$ and PAO6852 $(\diamond)$, respectively, and PA06875 harbouring ptac-mucD+( $\diamond)$. (b) Growth curves of the $P$. aeruginosa muCA2 mutant PAO568 (O), its mucC:: $\mathrm{Gm}^{r}$ derivative, PAO6876 $(\mathrm{O})$, and PA06876 harbouring ptac-muCD ${ }^{+}$ $(\diamond)$ (c) Growth curves of PA06857 (mucB::TC') (O) and PAO6877 (mucB:: $\mathrm{Tc}^{\mathrm{r}}$ mucC:: $\mathrm{Gm}^{\mathrm{r}}$ ) (O). All strains were grown at $42{ }^{\circ} \mathrm{C}$ in LB supplemented with either $300 \mathrm{mM} \mathrm{NaCl}$ or $30 \%$ sucrose as indicated.
\end{abstract}

aeruginosa (e.g. PAO568 and PAO6857) are mucoid on PIA, they are non-mucoid on LB unless this medium is supplemented with salt, with maximum alginate production in PAO568 at $300 \mathrm{mM} \mathrm{NaCl}$ (Deretic et al., 1990). Since salt concentration seemed to play a role in induction of mucoidy in $m u c A$ and $m u c B$ mutants while $m u c C$ had an effect (albeit at an elevated temperature) on $P$. aeruginosa growth in high ionic strength media, it appeared reasonable to test whether $m u c C$ inactivation would have an effect on alginate production under such conditions. In experiments carried out to explore these possibilities, induction of alginate production and significant morphological differences (i.e. mucoid phenotype in mucC mutants vs. slightly mucoid or non-mucoid phenotype in parental $m u c C^{+}$strains) were observed on media supplemented with two different osmolytes $(\mathrm{NaCl}$ and sucrose) (Table 2).

Interestingly, mucC inactivation in the $m u c A$ parent expressed its effect specifically when $\mathrm{NaCl}$ was used, while its inactivation in the mucB parent caused an effect when sucrose was used as an osmolyte (Table 2). This observation suggested a degree of specificity and differences in effects of double mucA mucC and $m u c B m u c C$ mutations. In combination with the mucA2 allele, inactivation of $m u c C$ (strain PAO6876) caused a significant increase in alginate production [from 4.15 to $14 \cdot 19 \mu \mathrm{g}(\mathrm{mg} \text { wet cell } \mathrm{wt})^{-1}$ ] on LB supplemented with $90 \mathrm{mM} \mathrm{NaCl}$ at $42{ }^{\circ} \mathrm{C}$ relative to the parental strain PAO568 (mucA2). The use of $90 \mathrm{mM} \mathrm{NaCl}$ (instead of $300 \mathrm{mM} \mathrm{NaCl}$ ) was optimal for the detection of the effects of mucC inactivation on alginate production in the mucA2 background. Strain PAO6877 (mucB::Tc ${ }^{\mathrm{r}}$ $m u c C:: \mathrm{Gm}^{\mathrm{r}}$ ) displayed increased alginate production [a change from 1.47 in the $m u c C^{+}$parent to $7.06 \mu \mathrm{g}(\mathrm{mg}$ wet cell wt $)^{-1}$ in $m u c C:: \mathrm{Gm}^{\mathrm{r}}$ cells] and mucoid phenotype when grown in the presence of $30 \%$ sucrose at $42^{\circ} \mathrm{C}$. The parental strain PAO6857 (mucB:: $\mathrm{Tc}^{\mathrm{r}}$ $m u c C^{+}$) remained non-mucoid under identical conditions (Table 2). These differences were not observed when the incubation temperature was $37^{\circ} \mathrm{C}$ (data not shown). The effect of mucC mutation could not be attributed to a polar effect on mucD since expression of plasmid-borne mucD (known to complement mucoidy in mucD mutants; Boucher et al., 1996) did not suppress mucoidy in PAO6877 (Table 2). These results suggest that $m u c C$ has a negative regulatory role in alginate production, which becomes appreciable only in the presence of $m u c A$ or $m u c B$ mutations and under a combination of adverse growth conditions.

\section{Additive effects of mucA and mucB mutations}

The results with $m u c C$ inactivation suggest that the muc genes have additive effects on alginate production and that $m u c C$ may act synergistically with $m u c A$ or $m u c B$. A further example of cumulative effects of the inactivation of negative regulators in the algU mucABCD gene cluster was observed when $m u c B$ was insertionally inactivated in the mucA2 background. The mucA2 $m u c B$ double mutant assumed a mucoid phenotype under conditions which rendered single mutant strains (mucA2 or $m u c B:: \mathrm{Tc}^{\mathrm{r}}$ ) non-mucoid (Table 3 ).

\section{DISCUSSION}

In this study we have examined the role of $m u c C$ in alginate production and in general resistance to stress in $P$. aeruginosa. Interestingly, $m u c C$ expresses its negative effect on alginate production under similar environmental conditions which impose a requirement for $m u c C$ to maintain full stress tolerance. However, the inhibition of growth in mucC mutants was neither the cause nor a prerequisite for increased alginate production. For example, mucoidy was not induced in PAO6875 (the mucC:: $\mathrm{Gm}^{r}$ derivative of PAO1) al- 
Table 3. Additive effects of mucA and mucB mutations on alginate production in $P$. aeruginosa

\begin{tabular}{|lccc|}
\hline Strain $\dagger$ & Genotype & Phenotype $\neq$ & $\begin{array}{c}\text { Alginate production } \\
{\left[\boldsymbol{\mu g}(\mathbf{m g} \text { wet wt of cells })^{-1} \pm \mathrm{SE}\right] \mathbb{S}}\end{array}$ \\
\hline PAO568 & $m u c A 2$ & $\mathrm{NM}$ & $1 \cdot 87 \pm 0 \cdot 04$ \\
PAO6857 & $m u c B:: \mathrm{Tc}^{\mathrm{r}}$ & $\mathrm{NM}$ & $1 \cdot 58 \pm 0 \cdot 11$ \\
PAO6858 & $m u c A 2 m u c B:: \mathrm{Tc}^{\mathrm{r}}$ & $\mathrm{M}^{*}$ & $3 \cdot 83 \pm 0 \cdot 09$ \\
\hline
\end{tabular}

†PAO6858 is a mucB:: $\mathrm{Tc}^{\mathrm{r}}$ derivative of PAO568.

$\ddagger$ Phenotypes of PAO568, PAO6857 and PAO6858 on LB medium: NM, non-mucoid; $M^{*}$, mucoid after 48 h. PAO568 and PAO6857 are mucoid on PIA (Table 2). All incubations were at $37^{\circ} \mathrm{C}$.

$\$$ The $P$ value $(t$ test $)$ was $3.23 \times 10^{-5}$ for PAO568 and PAO6858.

though the growth was retarded in this strain at levels similar to those in PAO6876 (mucA2 mucC:: $\mathrm{Gm}^{\mathrm{r}}$ ) (Fig. $2 \mathrm{a}$ and $\mathrm{b})$. Furthermore, mucoidy was induced in PAO6877 (mucB:: $\mathrm{Tc}^{\mathrm{r}} m u c \mathrm{C}:: \mathrm{Gm}^{\mathrm{r}}$ ) in the presence of $30 \%$ sucrose at $42{ }^{\circ} \mathrm{C}$ while growth was not significantly reduced relative to the $\mathrm{mucC}^{+}$parent (Fig. 2c). It is not possible to exclude the possibility that the new negative regulator of mucoidy, mucC, reported in this study also plays a positive regulatory role under certain environmental conditions or in genetic backgrounds different from those tested in this study. For example, recent studies by Missiakas et al. (1997), have indicated a possible positive effect of RseC, the E. coli homologue of MucC, on $\sigma^{\mathrm{E}}$-dependent transcription, albeit such effects were not corroborated by De Las Penas et al. (1997).

In one model that is currently being considered, it is possible that the effects of MucC are exerted via its putative role in the control of AlgU activity along with the other Muc factors. In this scenario, MucC may help direct AlgU to enhance the expression of factors necessary for survival under conditions of high ionic strength/osmotic shock at high temperature which could compete with the alg system for the available AlgU. Alternatively, MucC could be an effector which, in a fashion similar to that proposed for MucD, may remove or neutralize signals that induce AlgU activity (e.g. denatured proteins or other products of thermal and osmotic shock). While elimination of such putative inducing molecules may improve bacterial viability, at the same time such events may reduce AlgU activity, thus negatively affecting alginate production. However, unlike MucD which shows significant similarity with the serine protease HtrA (DegP) (Lipinska et al., 1988; Strauch \& Beckwith, 1988), MucC has no obvious motifs that would suggest such a function.

A modulatory role for $\mathrm{MucC}$ affecting interactions between the $\sigma$ factor AlgU (Martin et al., 1993c; Schurr et al., 1996; Xie et al., 1996), the anti- $\sigma$ factor MucA (Schurr et al., 1996; Xie et al., 1996) and the periplasmic protein MucB (Schurr et al., 1996) must also be considered. The transduction of signals between the periplasmic compartment [where MucB is located (Schurr et al., 1996)] and the cytoplasmic compartment where the $\sigma$ factor activity of $\mathrm{AlgU}$ is expressed may require complicated multi-component machinery. In that regard we have noticed two potential transmembrane domains in MucC (aa 76-99 and 104-123) which are also predicted for all of its homologues (Fig. 1b). In a model that takes into account a possible membrane association of MucC, this factor could transduce stress signals to the other components inhibiting $\mathrm{AlgU}$ activity and modulate their action. Further experiments are needed to determine the precise role of $\mathrm{MucC}$ and to discern between direct and indirect effects that its inactivation may have on the physiology of the cell which could have broader implications for those Gramnegative organisms that have MucC equivalents (Fig. 1a)

If $\mathrm{AlgU}$ is unchecked and overexpressed in the absence of at least one of its negative regulators, it becomes toxic to the cell (Schurr et al., 1994). In this context, the apparent redundancies in the system may have evolved as a mechanism for reducing the likelihood of events leading to runaway $\mathrm{AlgU}$. Furthermore, overexpression of the alginate system in wild-type cells may not be desirable unless precise environmental conditions are met, e.g. biofilm formation (Lam et al., 1980), or defence against extreme stress conditions is needed (Boucher et al., 1996; Martin et al., 1994; Yu et al., 1995). In support of these considerations is the lack or only rare occurrence of mucoid variants among environmental isolates (Anastassiou et al., 1987; Pier et al., 1986). In clinical situations, such as in cystic fibrosis, under strong selective pressures during prolonged chronic infections, mucoid mutants may be selected as the result of a compromise between the survival in the lung infiltrated with phagocytic cells (Speert, 1994) and the loss of adaptation flexibility or some toxicity of AlgU.

\section{ACKNOWLEDGEMENTS}

This work was supported by grants AI31139 from the National Institute for Allergy and Infectious Diseases and DERETI96PO from the Cystic Fibrosis Foundation. M. Schurr was 
supported by grant SCHURR95IO from the Cystic Fibrosis foundation. D. W. Rowen and H. Yu were Cystic Fibrosis Foundation postdoctoral fellows.

\section{REFERENCES}

Anastassiou, E. D., Mintzas, A. C., Kounavis, C. \& Dimitracopoulos, G. (1987). Alginate production by clinical nonmucoid Pseudomonas aeruginosa. J Clin Microbiol 25, 656-659.

Boucher, J. C., Martinez-Salazar, J. M., Schurr, M. J., Mudd, M. H., Yu, H. \& Deretic, V. (1996). Two distinct loci affecting conversion to mucoidy in Pseudomonas aeruginosa in cystic fibrosis encode homologs of the serine protease HtrA. J Bacteriol 178, 511-523.

Chi, E. \& Bartlett, D. H. (1995). An rpoE-like locus controls outer membrane protein synthesis and growth at cold temperature and high pressures in the deep-sea bacterium Photobacterium sp. strain SS9. Mol Microbiol 17, 713-726.

Coyne, M. J., Russell, K. S., Coyle, C. L. \& Goldberg, J. B. (1994). The Pseudomonas aeruginosa algC gene encodes phosphoglucomutase, required for the synthesis of a complete lipopolysaccharide core. J Bacteriol 176, 3500-3507.

De Las Penas, A., Connolly, L. \& Gross, C. A. (1997). The $\sigma^{\mathrm{E}}$ mediated response to extracytoplasmic stress in Escherichia coli is transduced by RseA and RseB, two negative regulators of $\sigma^{\mathrm{E}}$. Mol Microbiol 24, 373-385.

Deretic, V., Govan, J. R., Konyecsni, W. M. \& Martin, D. W. (1990). Mucoid Pseudomonas aeruginosa in cystic fibrosis: mutations in the muc loci affect transcription of the $\operatorname{alg} R$ and $\operatorname{alg} D$ genes in response to environmental stimuli. Mol Microbiol 4, 189-196.

Deretic, V., Schurr, M. J., Boucher, J. C. \& Martin, D. W. (1994). Conversion of Pseudomonas aeruginosa to mucoidy in cystic fibrosis : environmental stress and regulation of bacterial virulence by alternative sigma factors. J Bacteriol 176, 2773-2780.

Deretic, V., Schurr, M. J. \& Yu, H. (1995). Pseudomonas aeruginosa, mucoidy and chronic infection phenotype in cystic fibrosis. Trends Microbiol 3, 351-356.

DeVries, C. A. \& Ohman, D. E. (1994). Mucoid-to-nonmucoid conversion in alginate-producing Pseudomonas aeruginosa often results from spontaneous mutations in alg $T$, encoding a putative alternate sigma factor, and shows evidence for autoregulation. $J$ Bacteriol 176, 6677-6687.

Elzer, P. H., Phillips, R. W., Robertson, G. T. \& Roop, R. M., III (1996). The HtrA stress response protease contributes to resistance of Brucella abortus to killing by murine phagocytes. Infect Immun 64, 4838-4841.

Erickson, J. W. \& Gross, C. A. (1989). Identification of the sigma subunit of Escherichia coli polymerase: a second sigma factor involved in high-temperature gene expression. Genes Dev 3, 1462-1471.

Fyfe, J. A. M. \& Govan, J. R. W. (1980). Alginate synthesis in mucoid Pseudomonas aeruginosa: a chromosomal locus involved in control. J Gen Microbiol 119, 443-450.

Goldberg, J. B., Gorman, W. L., Flynn, J. \& Ohman, D. E. (1993). A mutation in algN permits trans activation of alginate production by algT in Pseudomonas species. J Bacteriol 175, 1303-1308.

Govan, J. R. W. \& Deretic, V. (1996). Microbial pathogenesis in cystic fibrosis: mucoid Pseudomonas aeruginosa and Burkholderia cepacia. Microbiol Rev 60, 539-574.

Johnson, K., Charles, I., Dougan, G., Pickard, D., O'Gaora, P., Costa, G., Ali, T., Miller, I. \& Hormaeche, C. (1991). The role of a stress-response protein in Salmonella typhimurium virulence. Mol Microbiol 5, 401-407.
Knutson, C. A. \& Jeanes, A. (1976). A new modification of the carbazole reaction: application to heteropolysaccharides. Anal Biochem 24, 470-481.

Lam, J., Chan, R., Lam, K. \& Costerton, J. W. (1980). Production of mucoid microcolonies by Pseudomonas aeruginosa within infected lungs in cystic fibrosis. Infect Immun 28, 546-556.

Lipinska, B., Sharma, S. \& Georgopoulos, C. (1988). Sequence analysis and regulation of the $h t r A$ gene of Escherichia coli: a $\sigma^{32}$ independent mechanism of heat-inducible transcription. Nucleic Acids Res 16, 10053-10067.

Lonetto, M. A., Brown, K. L., Rudd, K. E. \& Buttner, M. J. (1994). Analysis of the Streptomyces coelicolor sigE gene reveals the existence of a subfamily of eubacterial RNA polymerase $\sigma$ factors involved in the regulation of extracytoplasmic functions. Proc Natl Acad Sci USA 86, 7573-7577.

Martin, D. W., Holloway, B. W. \& Deretic, V. (1993a). Characterization of a locus determining the mucoid status of Pseudomonas aeruginosa: AlgU shows sequence similarities with a Bacillus sigma factor. J Bacteriol 175, 1153-1164.

Martin, D. W., Schurr, M. J., Mudd, M. H. \& Deretic, V. (1993b). Differentiation of Pseudomonas aeruginosa into the alginateproducing form: inactivation of $m u c B$ causes conversion to mucoidy. Mol Microbiol 9, 497-506.

Martin, D. W., Schurr, M. J., Mudd, M. H., Govan, J. R. W., Holloway, B. W. \& Deretic, V. (1993C). Mechanism of conversion to mucoidy in Pseudomonas aeruginosa infecting cystic fibrosis patients. Proc Natl Acad Sci USA 90, 8377-8381.

Martin, D. W., Schurr, M. J., Yu, H. \& Deretic, V. (1994). Analysis of promoters controlled by the putative sigma factor AlgU regulating conversion to mucoidy in Pseudomonas aeruginosa: relationship to stress response. J Bacteriol 176, 6688-6696.

May, T. B. \& Chakrabarty, A. M. (1994). Pseudomonas aeruginosa: genes and enzymes of alginate synthesis. Trends Microbiol 2, 151-157.

Mecsas, J., Rouviere, P. E., Erickson, J. W., Donohue, T. J. \& Gross, C. A. (1993). The activity of $\sigma^{\mathbf{E}}$, an Escherichia coli heat-inducible $\sigma$-factor, is modulated by expression of outer membrane proteins. Genes Dev 7, 2618-2628.

Missiakas, D., Mayer, M. P., Lemaire, M., Georgopoulos, C. \& Raina, S. (1997). Modulation of the Escherichia coli $\sigma^{\mathrm{E}}$ (RpoE) heat-shock transcription-factor activity by the RseA, RseB and RseC proteins. Mol Microbiol 24, 355-371.

Mohr, C. D. \& Deretic, V. (1990). Gene-scrambling mutagenesis: generation and analysis of insertional mutations in the alginate regulatory region of Pseudomonas aeruginosa. J Bacteriol 172, $6252-6260$.

Pier, G. B., DesJardins, D., Aquilhar, R., Barnard, M. \& Speert, D. (1986). Polysaccharide surface antigens expressed by nonmucoid isolates of Pseudomonas aeruginosa from cystic fibrosis patients. J Clin Microbiol 24, 189-196.

Raina, S., Missiakas, D. \& Georgopoulos, C. (1995). The rpoE gene encoding the $\sigma^{\mathrm{E}}\left(\sigma^{24}\right)$ heat shock sigma factor of Escherichia coli. EMBO J 14, 1043-1055.

Rouviére, P. E., De Las Penas, A., Mecsas, J., Lu, C. Z., Rudd, K. E. \& Gross, C. A. (1995). $r p o E$, the gene encoding the second heatshock sigma factor, $\sigma^{\mathrm{E}}$, in Escherichia coli. EMBO $J 14$, 1032-1042.

Schurr, M. J., Martin, D. W., Mudd, M. H. \& Deretic, V. (1994). Gene cluster controlling conversion to alginate-overproducing phenotype in Pseudomonas aeruginosa: functional analysis in a heterologous host and role in the instability of mucoidy. J Bacteriol 176, 3375-3382. 
Schurr, M. J., Yu, H., Boucher, J. C., Hibler, N. S. \& Deretic, V. (1995). Multiple promoters and induction by heat shock of the gene encoding the alternative sigma factor $\operatorname{Alg} U\left(\sigma^{\mathbf{E}}\right)$ which controls mucoidy in cystic fibrosis isolates of Pseudomonas aeruginosa. J Bacteriol 177, 5670-5679.

Schurr, M. J., Yu, H., Martinez-Salazar, J. M., Boucher, J. C. \& Deretic, V. (1996). Control of AlgU, a member of the $\sigma^{\mathrm{E}}$-like family of stress sigma factors, by the negative regulators MucA and MucB and Pseudomonas aeruginosa conversion to mucoidy in Cystic Fibrosis. J Bacteriol 178, 4997-5004.

Speert, D.P. (1994). Pseudomonas aeruginosa infections in patients with cystic fibrosis. In Pseudomonas aeruginosa Infections and Treatment, pp. 183-236. Edited by A. L. Baltch \& R. P. Smith. New York: Marcel Dekker, Inc.

Strauch, K. \& Beckwith, J. (1988). An Escherichia coli mutation preventing degradation of abnormal periplasmic proteins. Proc Natl Acad Sci USA 85, 1576-1580.

Wozniak, D. J. \& Ohman, D. E. (1994). Transcriptional analysis of the Pseudomonas aeruginosa genes $\operatorname{alg} R, \operatorname{alg} B$ and $\operatorname{alg} D$ reveals a hierarchy of alginate gene expression which is modulated by algT. J Bacteriol 176, 6007-6014.
Wu, J. \& Weiss, B. (1991). Two divergently transcribed genes, soxR and soxS, control a superoxide response regulon of Escherichia coli. J Bacteriol 173, 2864-2871.

Yu, H., Schurr, M. J., Boucher, J. C., Martinez-Salazar, J. M., Martin, D. W. \& Deretic, V. (1996). Molecular mechanism of conversion to mucoidy in Pseudomonas aeruginosa. In Pseudomonas, pp. 384-397. Edited by S. Silver, T. Nakazowa \& D. Haas. Washington, DC: American Society for Microbiology.

Yu, H., Schurr, M. J. \& Deretic, V. (1995). Functional equivalence of Escherichia coli $\sigma^{\mathrm{E}}$ and Pseudomonas aeruginosa AlgU: E. coli $r p o E$ restores mucoidy and reduces sensitivity to reactive oxygen intermediates in algU mutants of $P$. aeruginosa. J Bacteriol 177, 3259-3268.

Xie, Z.-D., Hershberger, C. D., Shankar, S., Ye, R. W. \& Chakrabarty, A. M. (1996). Sigma factor-anti-sigma factor interaction in alginate synthesis: inhibition of Alg T by MucA.J Bacteriol 178, 4990-4996.

Received 17 March 1997; revised 4 July 1997; accepted 21 July 1997. 